\title{
Place of death, care-seeking and care pathway progression in the final illnesses of children under five years of age in sub-Saharan Africa: a systematic review
}

\author{
Jessica Price ${ }^{1}$, Joseph \\ Lee $^{1}$, Merlin Willcox ${ }^{2}$, \\ Anthony Harnden ${ }^{1}$ \\ ${ }^{1}$ Nuffield Department of Primary \\ Care Health Sciences, University \\ of Oxford, Oxford, UK \\ ${ }^{2}$ Department of Primary Care and \\ Population Medicine, University \\ of Southampton, Southampton, \\ UK
}

\begin{abstract}
Background Half of all under-5 deaths occur in sub-Saharan Africa. Reducing child mortality requires understanding of the modifiable factors that contribute to death. Social autopsies collect information about place of death, care-seeking and care-provision, but this has not been pooled to learn wider lessons. We therefore undertook a systematic review to collect, evaluate, map, and pool all the available evidence for sub-Saharan Africa.
\end{abstract}

Methods We searched PubMed, Embase, Global Health, the Cochrane Library and grey literature for studies relating to under-5 deaths in sub-Saharan Africa with information on place of death and/or care-seeking during a child's final illness. We assessed study quality with a modified Axis tool. We pooled proportions using random effects meta-analysis for place of death and for each stage of the Pathways to Survival framework. Pre-specified subgroup analysis included age group, national income and user-fee policy. We explored heterogeneity with meta-regression. Our protocol was published prospectively (CRD42018111484).

Results We included 34 studies from 17 countries. Approximately half of the children died at home, irrespective of age. More children died at home in settings with user-fees $\left(69.1 \%, 95 \%\right.$ confidence interval $(\mathrm{CI})=56.2-80.6, \mathrm{I}^{2}=98.4 \%$ ) compared to settings without user-fees $\left(43.8 \%, 95 \% \mathrm{CI}=34.3-53.5, \mathrm{I}^{2}=96.7 \%\right)$. Signs of illness were present in over $95 \%$ of children but care-seeking differed by age. $40.1 \%$ of neonates ( $95 \% \mathrm{CI}=20.7-61.3, \mathrm{I}^{2}=98.0 \%$ ) died without receiving any care, compared to $6.4 \%$ of older children ( $\left.95 \% \mathrm{CI}=4.2 \%-9.0 \%, \mathrm{I}^{2}=90.6 \%\right)$. Care-seeking outside the home was less common in neonatal deaths $(50.5 \%, 95 \%$ $\left.\mathrm{CI}=35.6-65.3, \mathrm{I}^{2}=98.3 \%\right)$ compared to infants and young children $(82.4 \%, 95 \%$ $\left.\mathrm{CI}=79.4 \%-85.2 \%, \mathrm{I}^{2}=87.5 \%\right)$. In both age groups, most children were taken for formal care. Healthcare facilities discharged $69.6 \%$ of infants and young children who arrived alive (95\% CI =59.6-78.7, $\mathrm{I}^{2}=95.5 \%$ ), of whom only $34.9 \%$ were referred for further care $\left(95 \% \mathrm{CI}=15.1-57.9, \mathrm{I}^{2}=98.7 \%\right)$.

Conclusions Despite similar distributions in place of death for neonates and infants and young children, care-seeking behaviour differed by age groups. Poor illness recognition is implicated in neonatal deaths, but death despite care-seeking implies inadequate quality care and referral for older children. Understanding such care-seeking patterns enables targeted interventions to reduce under-5 mortality across the region.

The under- 5 mortality rate in sub-Saharan Africa continues to be the highest in the world, with half of all under-5 deaths in 2017 occurring in this region despite representing only $13.9 \%$ of the global population [1,2]. The United Nations used Sus- 
tainable Development Goal 3.2 to set a target under- 5 mortality rate of 25 deaths per 1000 live births by 2030 [3]. However, weak vital registration systems in many countries across sub-Saharan Africa make it difficult to accurately estimate the number of births and deaths in a given year. This difficulty is compounded when births and deaths occur outside the health care system. Population based studies have shown that high proportions of under-5 deaths occur outside health facilities [4-6] though no work has yet attempted to systematically identify and pool these findings across countries in sub-Saharan Africa.

Place of death is just one social circumstance of death which can offer insights into modifiable factors contributing to under- 5 mortality. There has been increasing recognition of the importance of understanding the care-seeking behaviours and barriers faced by caregivers during a child's final illness. Traditionally these were explored by facility-based audits or confidential enquiries, but the past decade has seen a rise in the use of social autopsies as a population-based tool to investigate social circumstances of death [7]. A social autopsy is a structured interview with the caregiver of the deceased which attempts to make a "social diagnosis" of cause of death by identifying its cultural, social and health-systems antecedents $[5,8,9]$. Different social autopsy tools and frameworks for analysis have been developed [7].

The Pathways to Survival Framework is a commonly-used analytic framework in the study of care pathways in fatal childhood illness. First developed in 1996 and subsequently adapted, it provides a means of thinking through the processes of seeking and providing care both within and outside the home during a child's illness [10]. Despite the growing number of studies using this framework, individual studies do not give a sense of whether patterns identified apply across sub-Saharan Africa, nor whether there are characteristics which influence care-seeking processes universally.

In this review we aim to systematically gather and appraise all available evidence to 1 ) determine the proportion of under-5 deaths occurring within and outside health facilities in sub-Saharan Africa, 2) characterize the processes of seeking and providing care during the fatal illness, as defined by the Pathways to Survival framework and 3) to determine whether place of death or care-seeking behavior varied based on the age of the child, income status of the country or presence of user-fees.

\section{METHODS}

\section{Search strategy and selection criteria}

The systematic review protocol was prospectively published and is available from PROSPERO (PROSPERO 2018 CRD42018111484, http://www.crd.york.ac.uk/PROSPERO/display_record.php?ID=CRD42018111484).

We conducted a systematic search of the literature to identify studies relating to deaths of children under 5 years of age from sub-Saharan Africa, that included information on place of death and/or care-seeking behaviour during a child's final illness. We searched PubMed, Embase, Global Health and the Cochrane Library using the following search terms in various combinations: care pathway*, pathways to care, care-seeking, health care-seeking, treatment seeking, "pathway to survival", "three delay", social autopsy, verbal autopsy with terms to identify children under years (child, under-5 under 5, infant, neonat*, newborn) and countries in sub-Saharan Africa as defined by the World Bank [11]. Mesh terms were included where appropriate. The final search was conducted on 15 August 2018. We also conducted a manual review of the reference lists of relevant articles to identify any additional resources that should be included and contacted leading authors in the field to identify relevant unpublished data.

We included studies if they were conducted in a country in sub-Saharan Africa, reporting on deaths in children under-5 years, and included data on at least one of the following:

1) The number or proportion of children who died at home

2) The number or proportion of children who died in a health facility

3) Treatment seeking behavior during the final illness, including one or more of the stages of care as identified by the pathways to survival framework (ie, recognition of illness, provision of care in the home, care-seeking outside the home from formal and informal providers, referral and acceptance of referral).

We excluded studies that focused only on stillbirths or did not separate stillbirths from neonatal or under-5 deaths, or if results were reported purely qualitatively. Review articles were not included as this systematic review focused on primary research, however they were used to confirm that relevant references were identified and included in the analysis. We didn't exclude articles based on publication date or language. 
Two reviewers (JP and JL) independently screened all titles and abstracts for relevance, then independently selected full texts for inclusion in the final review. Discrepancies were resolved by consensus. Data from each included study were independently extracted by the same reviewers and cross checked using a standardized template to record details including country; age group (neonatal/1-59 months/under-5; total number of deaths; number of deaths at home, in health facilities, on route to facilities or elsewhere; and care-seeking data (broken down into the stages identified by the Pathways to Survival framework). Where the published manuscript did not disaggregate the data in a way that could be aligned to the criteria we used in this review, authors were contacted to ask for a more detailed breakdown of the original data.

\section{Quality appraisal}

We adapted the AXIS tool for cross-sectional studies to allow us to assess study quality [12] (Appendix 1 in Online Supplementary Document). This was necessary as we included studies with different objectives to our own as long as they reported data we could use. We adapted the scoring system retaining points relevant to data collection but removing points not relevant to our objectives (and thus to assessing those aspects of the study relevant to the inclusion of the data in the meta-analysis) eg, were the author's discussions and conclusions justified by the results. Quality indicators were also re-worded from the negative to the affirmative such that the presence of each indicator (which demonstrated improved quality) was associated with a higher score. For studies that had different aims and objectives to ours, we evaluated each quality indicator in relation to the aims and objectives of this review rather than the aim of the original study. Two reviewers independently assessed each study, awarding 1 point where the criterion was met, and resulting in a final score calculation as a proportion between 0 (poor quality) and 1 (high quality). Conflicts were agreed with discussion.

\section{Statistical analysis}

We pooled proportions using random effects meta-analysis, after the Freeman-Tukey Double Arcsine Transformation of variances, using Stata command metaprop [13]. We used score (Wilson) estimation to calculate $95 \%$ confidence intervals. We used the $\mathrm{I}^{2}$ statistic as our measure of statistical heterogeneity. We estimated proportions in pre-specified sub-groups according to age group (neonatal or infants and young children), national income status (low income, lower middle income and upper middle income), and the presence of user-fees in each country (yes/no). Where studies only reported results for under- 5 deaths overall, and we were unable to get an appropriate age breakdown after contacting

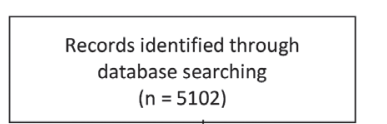

$(n=5102)$
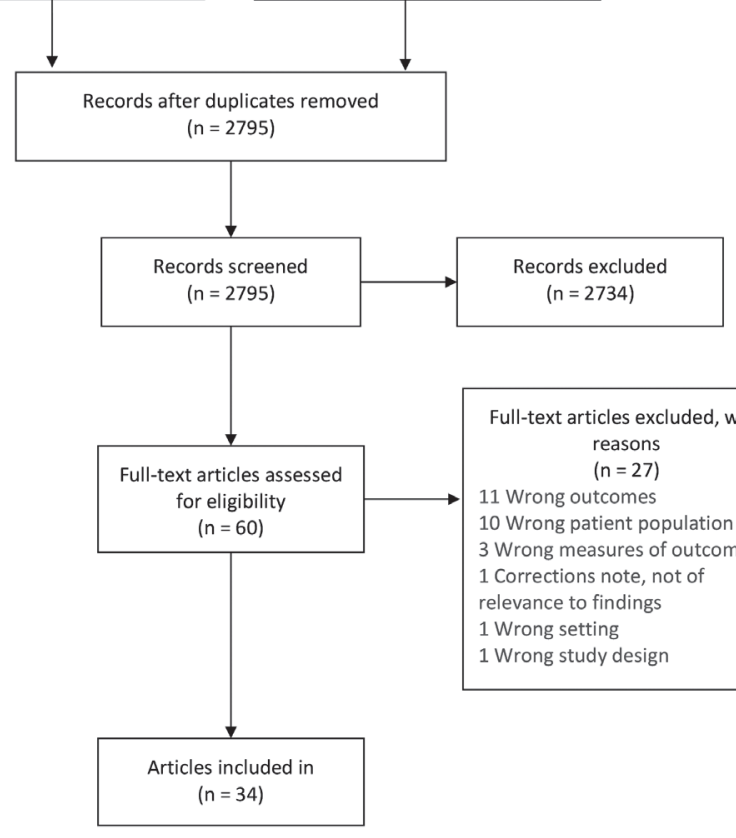
the authors of the original publication, we grouped this data with results for infants and young children.

We used random-effects meta-regression to explore heterogeneity, assessing the association between each outcome and age group, national income status and user-fee policy, using the Stata command metareg [14].

\section{RESULTS}

\section{Search}

The literature search found 5102 citations. After deduplication, 2794 citations remained for title and abstract screening. In addition, our review of reference lists identified one further research report that was included giving a total 2795 abstracts. After two reviewers independently screened all titles and abstracts, 60 studies were included for full text review, and 34 were included in the final analysis. (Figure 1).

Figure 1. PRISMA flow diagram [15]. 


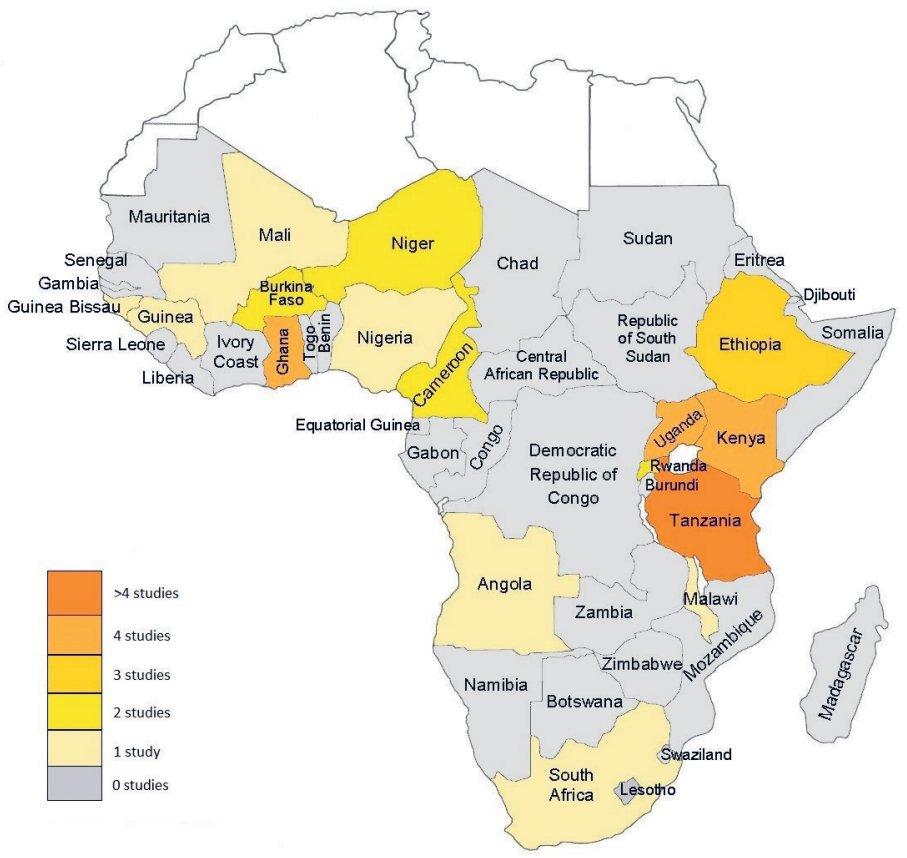

Figure 2. Map showing number and location of included studies.

\section{Included studies characteristics}

Characteristics of the included studies are summarised in Table 1. Sixteen studies reported on neonatal deaths, 22 on deaths of infants and young children and seven on overall under-5 deaths. Data was drawn from 17 countries (Figure 2), 13 low-income countries, 3 lower middle income countries and 1 upper middle income country. Sixteen studies were conducted in settings where user-fees are charged at government facilities at the point of care, while 21 were from settings where governments had abolished user-fees. In one study in Ghana [31], the user-fee policy was changed during the observation period, and in Nigeria [4] user-fee policy varies across states [47], and so both studies were excluded from the relevant sub-analysis.

\section{Quality appraisal}

Study quality ranged from 0.21-1.00 (Table S1 in Online Supplementary Document). The most common problems identified in the included studies were failing to report on all stages of the care pathway, failing to report the response rate and fail-

ing to categorise non-responders where the response rate was less than $90 \%$. Appropriate categorisation of non-responders included descriptions of age and other demographic details, and reasons for non-participation to allow an assessment of risk of bias.

\section{Synthesis of results}

Proportions varied between studies, and statistical heterogeneity in pooled estimates as estimated by $\mathrm{I}^{2}$ was high (Table S2 in Online Supplementary Document).

\section{Place of death}

As shown in Table 2 and Figure 3, place of death was similar across age groups. Approximately half of all children died at home $\left(53.2 \%\right.$ of neonates $95 \%$ confidence interval $(\mathrm{CI})=40.0-66.2, \mathrm{I}^{2}=97.5 \%$ and $53.1 \%$ of infants and young children $95 \% \mathrm{CI}=44.2-62.0, \mathrm{I}^{2}=98.0 \%$ respectively) and over a third died in health facilities (37.8\% of neonates, $95 \% \mathrm{CI}=26.4 \%-49.8 \%, \mathrm{I}^{2}=97.0 \%$ and $33.4 \%$ of infants and young children, 95\% CI=25.5\%-41.9\%, $\mathrm{I}^{2}=97.6 \%$ ). Small fractions of deaths happened en route to a health care facility or elsewhere.

The place of death did not vary significantly by national income status (Table S2 and Appendix S4 in Online Supplementary Document). Countries where user-fees were charged appeared to have a bimodal distribution of home deaths (Appendix S4 in Online Supplementary Document). Therefore, while a comparison of pooled proportions across settings with and without user-fees would suggest that user-fees are associated with a higher proportion of home deaths (Table S3 and Appendix S4 in Online Supplementary Document), this should be interpreted with caution.

\section{Care pathways analysis - curative care-seeking}

Patterns of care-seeking were different for neonates and older children, as shown in Table 2 and Figures 4 to 7 .

\section{Home and travel to care}

Over 95\% of caregivers of neonates and infants and young children recognized their child was unwell and over 80\% reported potentially serious signs (Figure 4). However, 40.1\% of neonates (95\% $\mathrm{CI}=20.7-61.3, \mathrm{I}^{2}=98.0 \%$ ) died without care of any sort being provided, whereas very few older children died with no care at all (6.4\% 95\% CI=4.2\%-9.0\%, $\mathrm{I}^{2}=90.6 \%$ ) (Figure 5). 14.4\% of neonates (95\% 


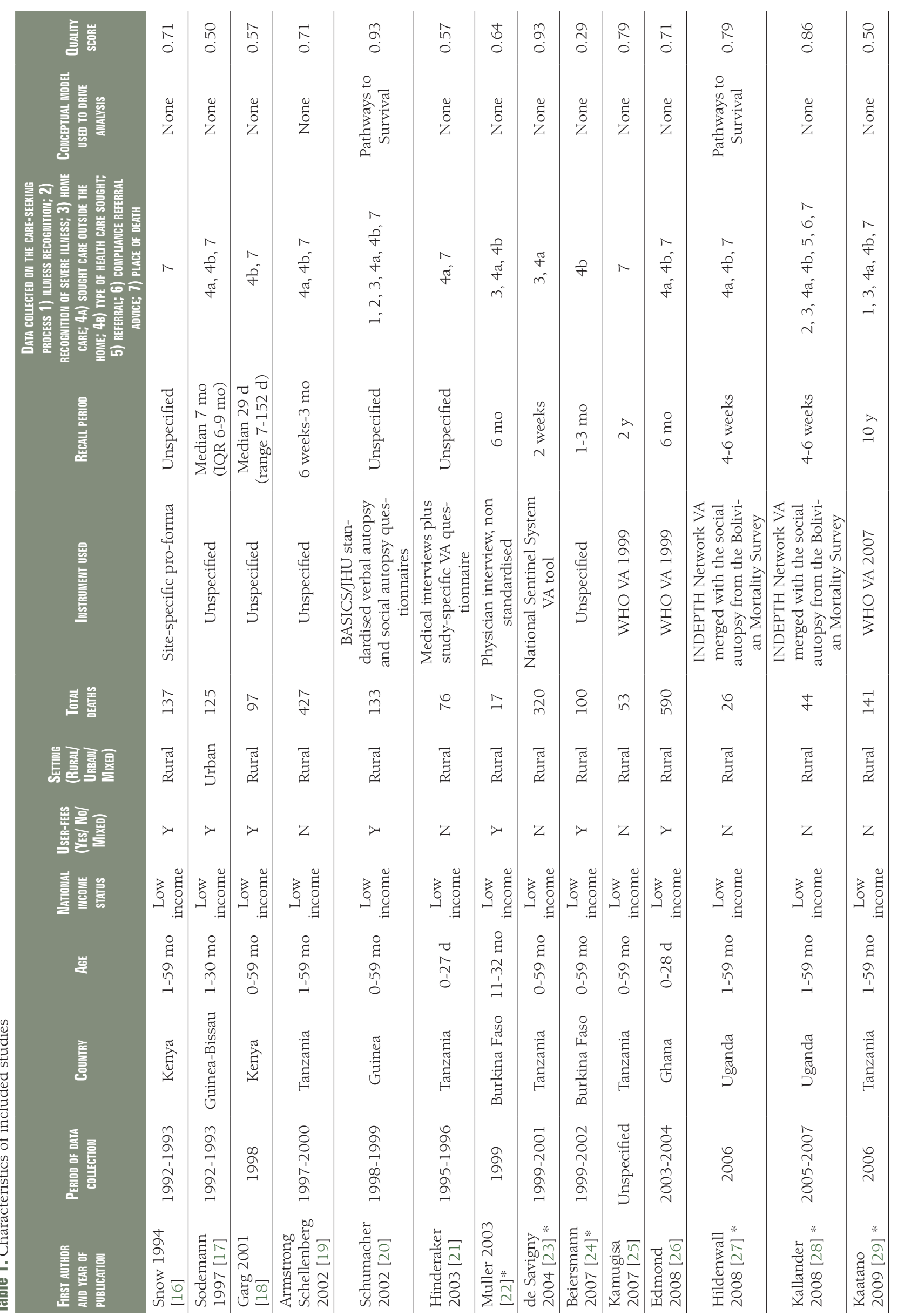




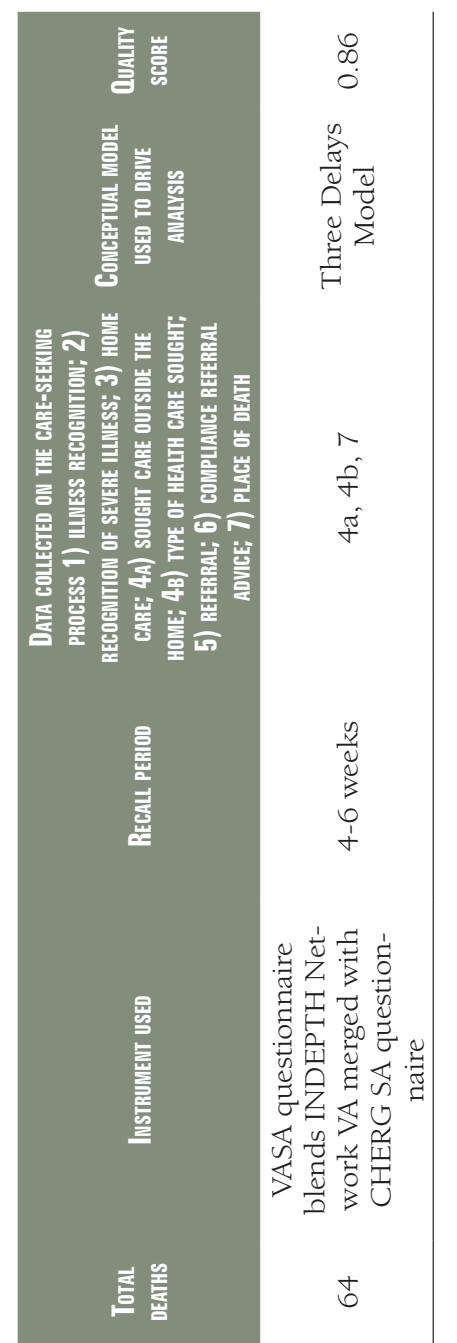

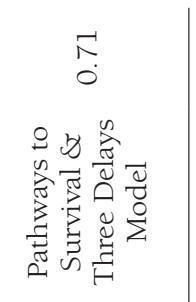

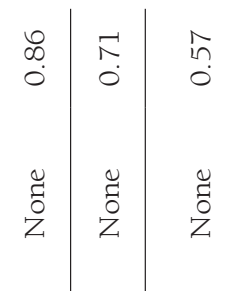

$\wedge$

in

के

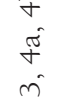

i

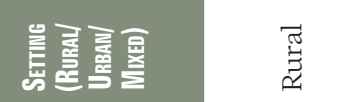

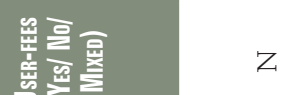

III

z气 है:

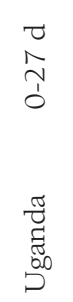

究苛

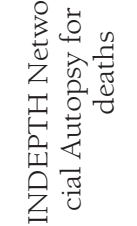

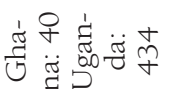

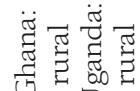

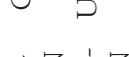

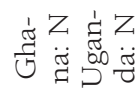

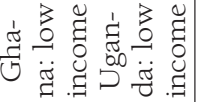

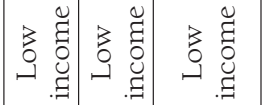

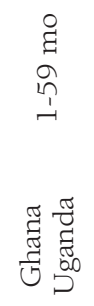

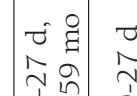

送

言

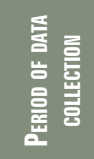

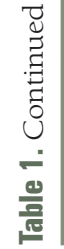

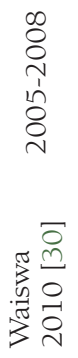

\begin{tabular}{|c|c|}
\hline $\begin{array}{l}\text { च } \\
\text { J్ }\end{array}$ & 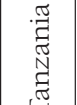 \\
\hline 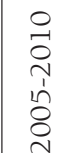 & $\begin{array}{l}\hat{o} \\
\dot{i} \\
i\end{array}$ \\
\hline 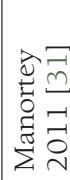 & 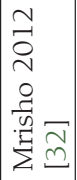 \\
\hline
\end{tabular}

ำ

$\infty$
$\infty$
0
0

:̆

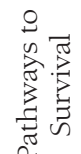

ช์

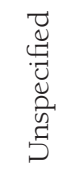

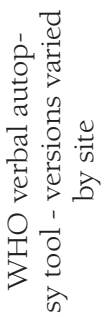

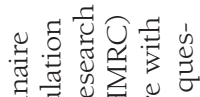

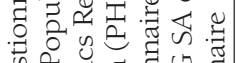

岛.

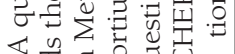

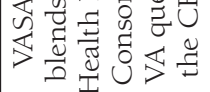

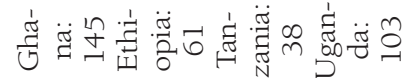

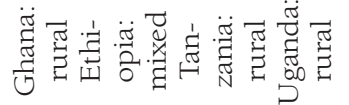

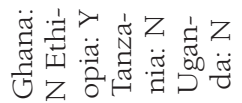

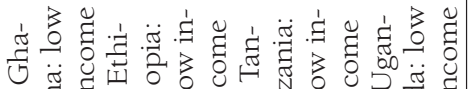

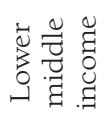

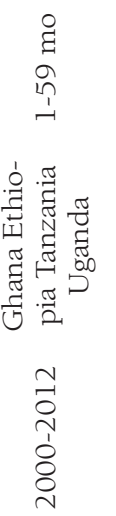

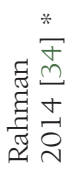

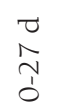

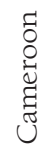

จี่

$\stackrel{+}{6}$

$\stackrel{\overrightarrow{\mathscr{x}}}{\stackrel{\widetilde{x}}{\Sigma}}$

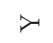

in

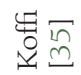




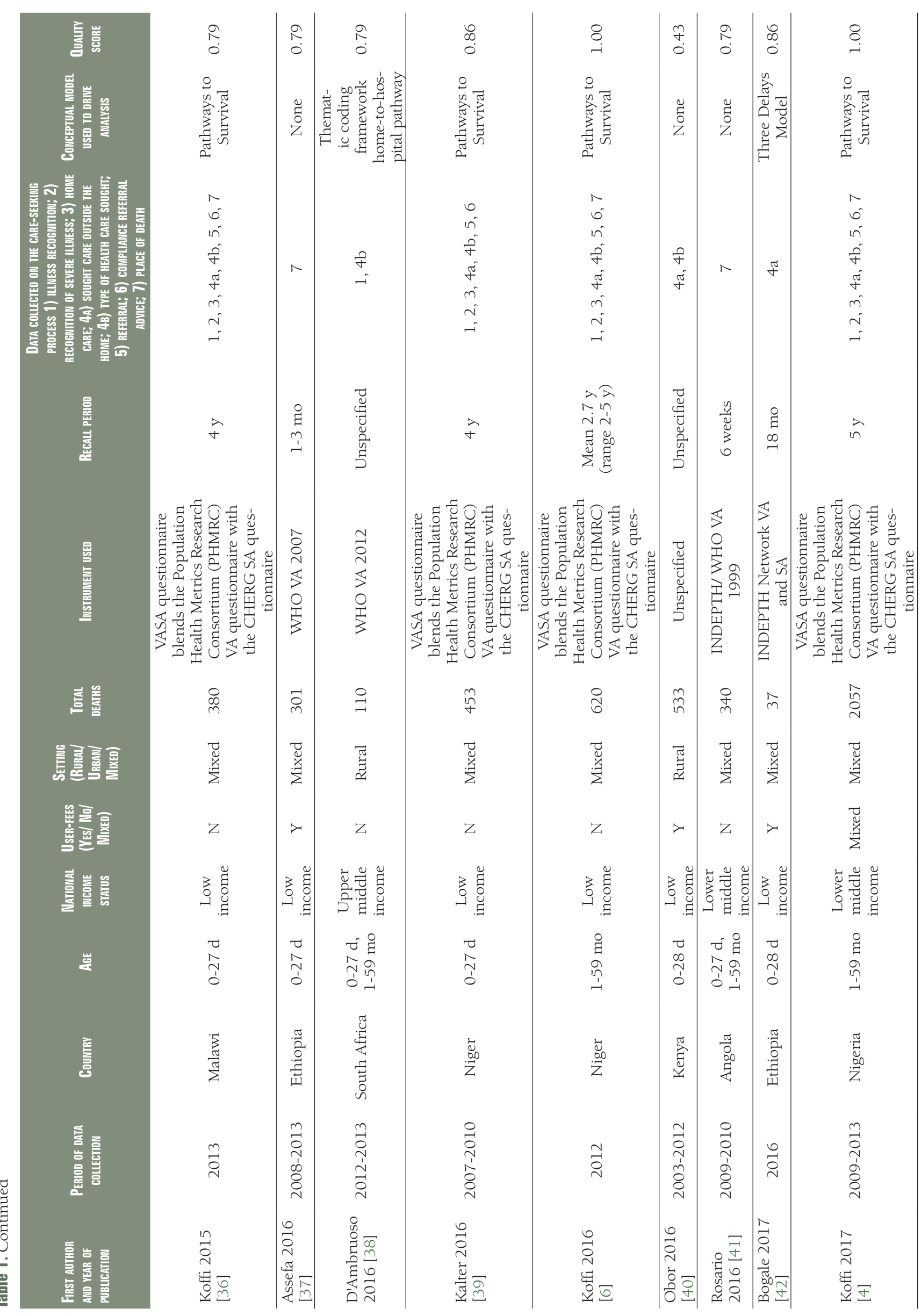



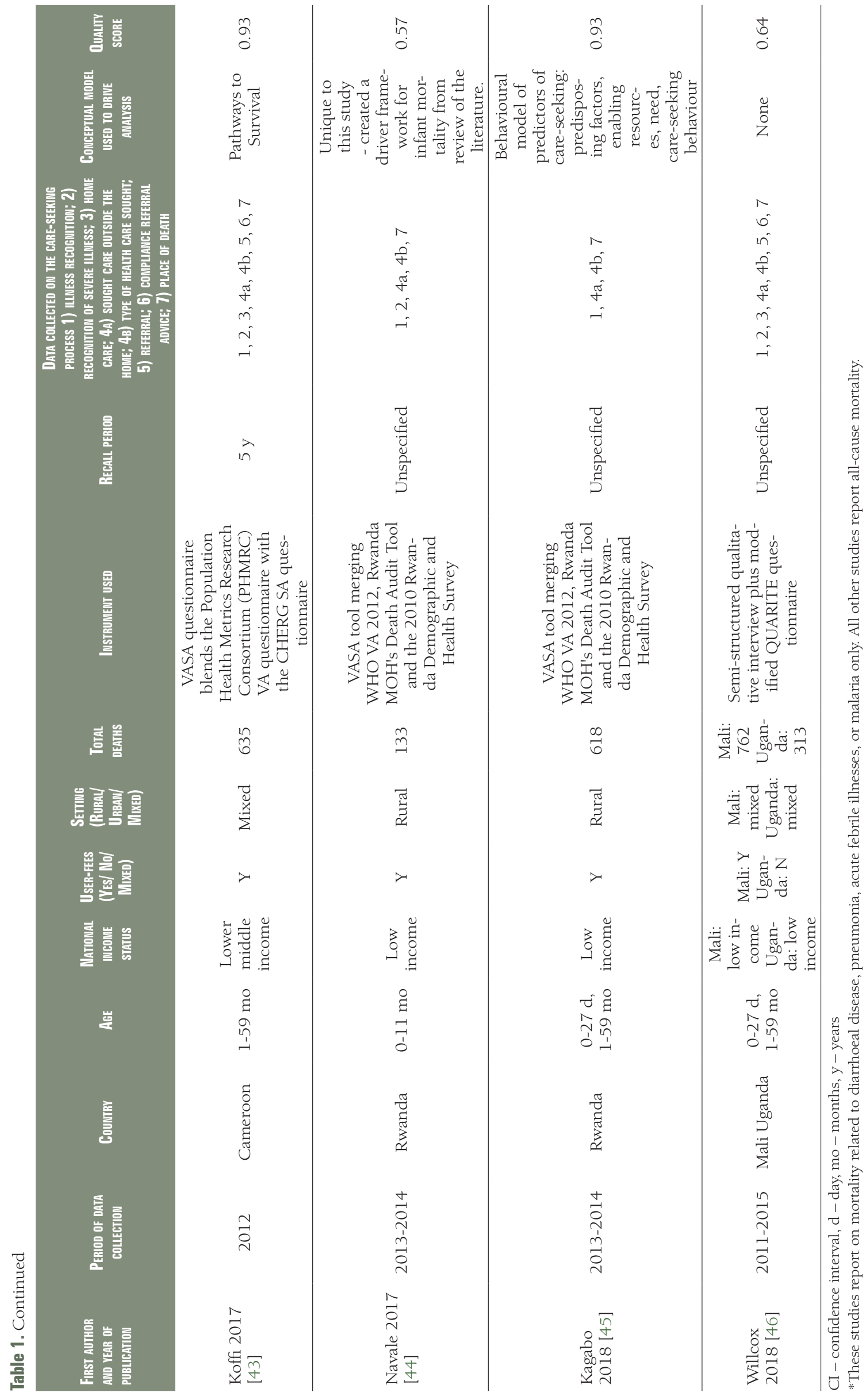

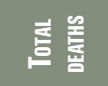

กิ้

琵琶量

気

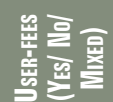

IIII

岩

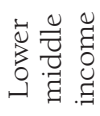

छ

in

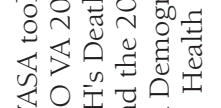

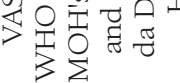

$\stackrel{m}{n}$



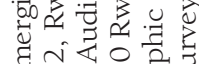

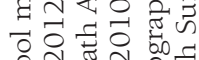

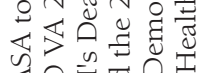

$>$ 年

$\stackrel{\infty}{6}$

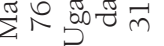

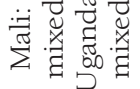

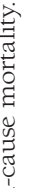

ज.

氙 


\section{Died at home}

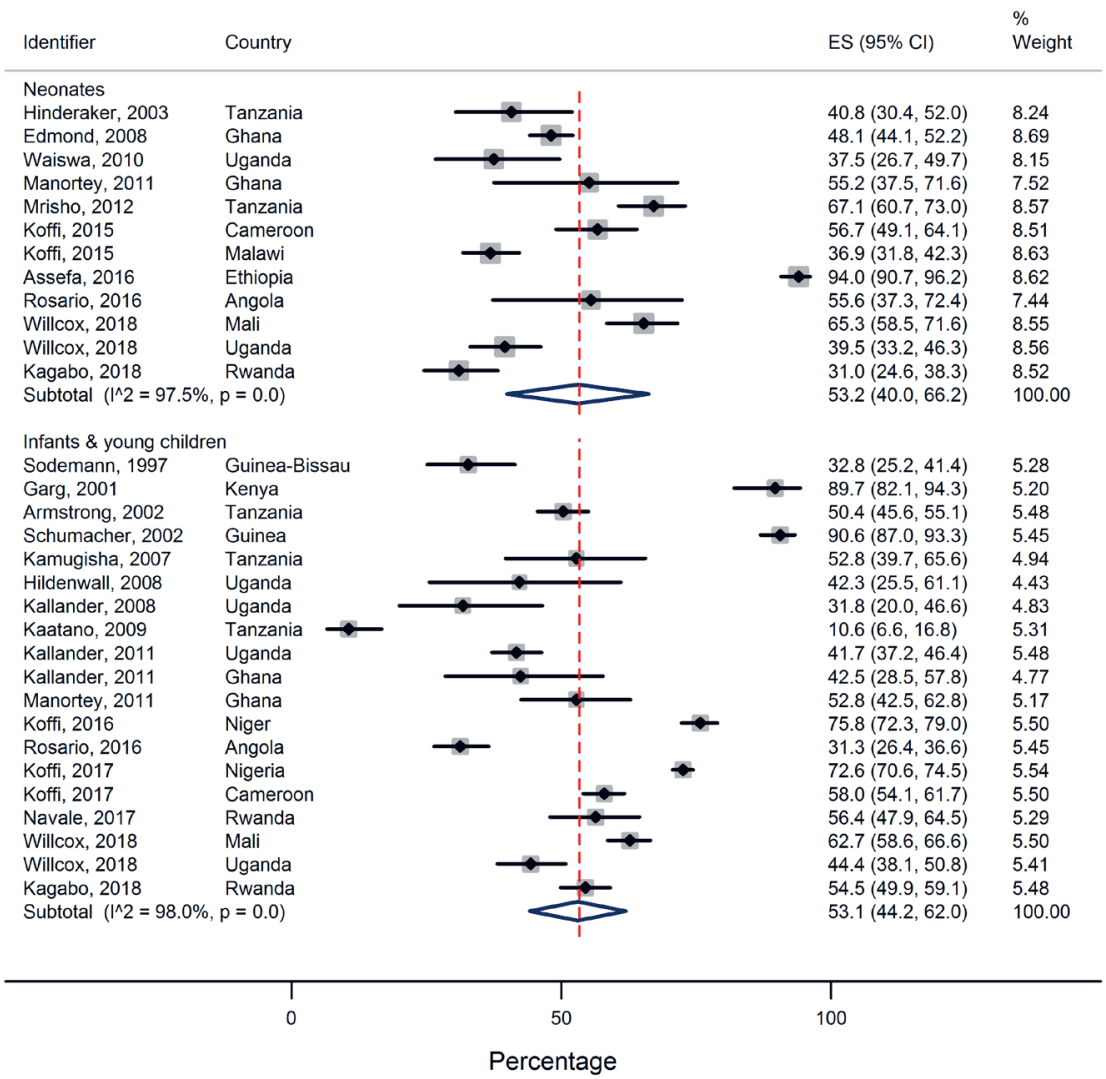

Figure 3. Proportion of children who died at home, by age group.

\section{Signs/symptoms of illness}

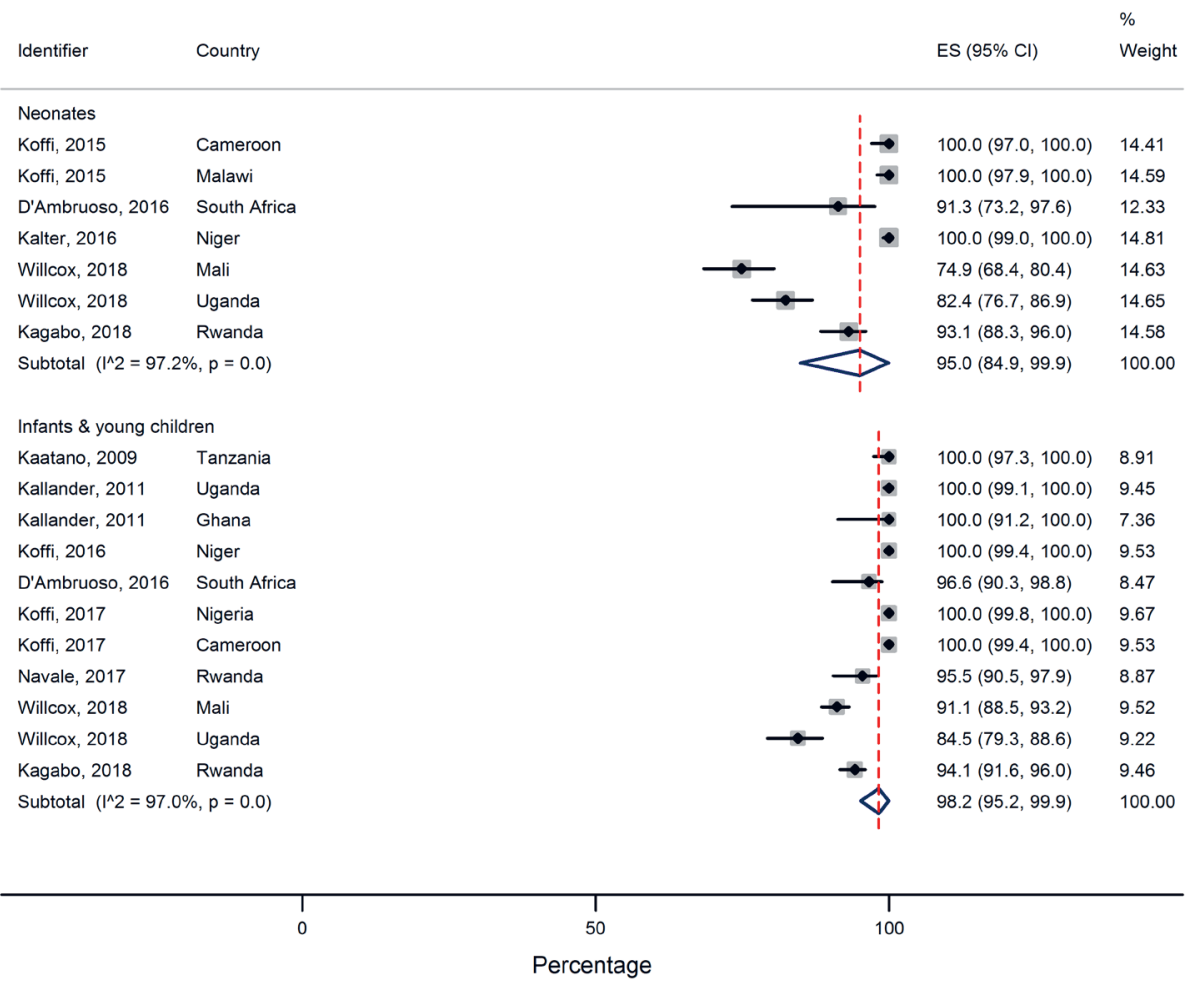

Figure 4. Proportion of children with signs/symptoms of illness, by age group. 


\section{Died immediately/no care given}

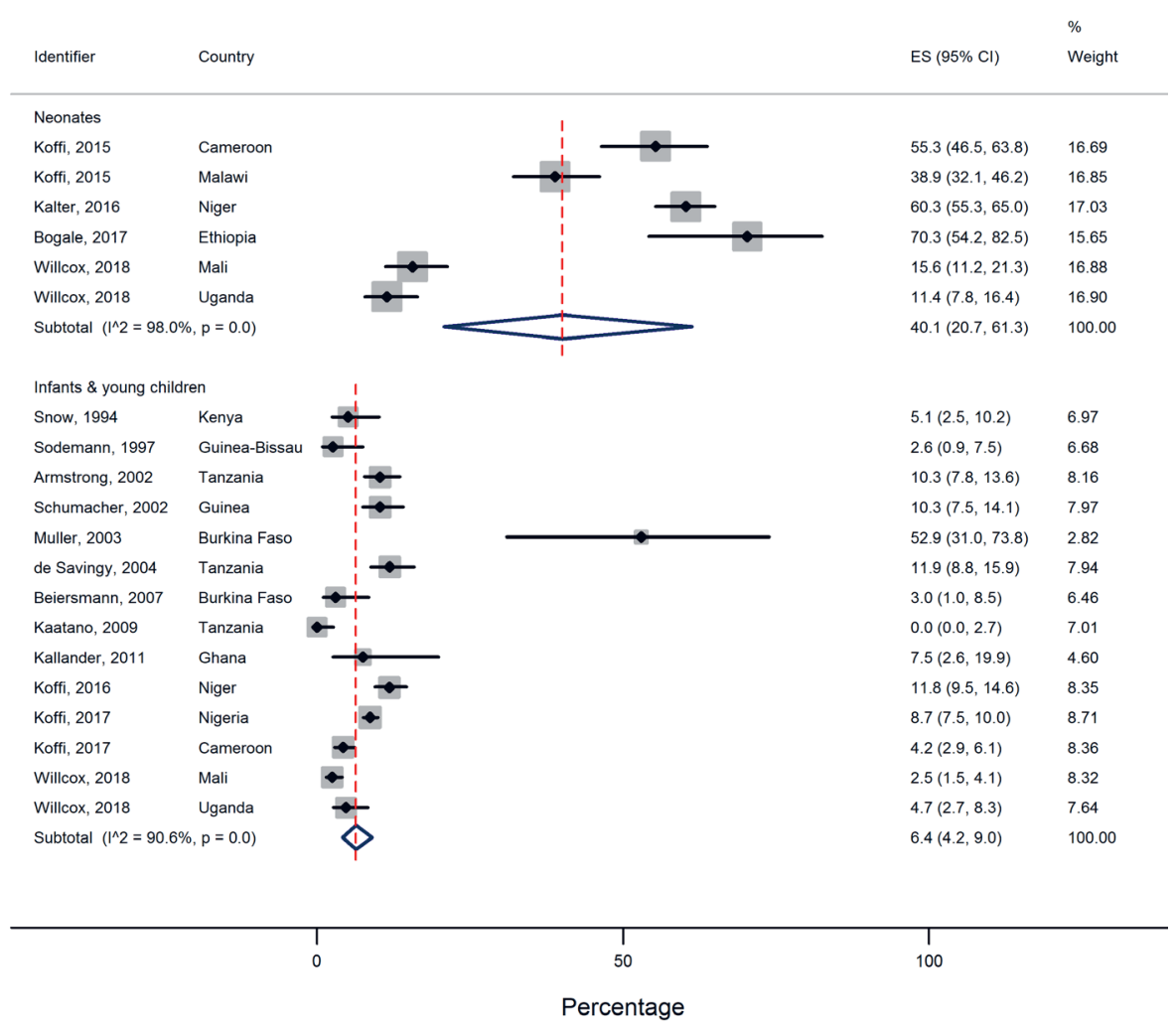

Figure 5. Proportion of children who died immediately or without receiving any care, by age group.

$\left.\mathrm{CI}=8.8 \%-21.0 \% \mathrm{I}^{2}=87.9 \%\right)$ received care in the home compared to over half of infants and young children $\left(52.6 \%, 95 \% \mathrm{CI}=37.8 \%-67.1 \%, \mathrm{I}^{2}=99.0 \%\right)$. Care-seeking outside the home was less common in neonatal deaths $\left(50.5 \%, 95 \% \mathrm{CI}=35.6-65.3, \mathrm{I}^{2}=98.3 \%\right)$ compared to infants and young children $(82.4 \%$, $95 \% \mathrm{CI}=79.4 \%-85.2 \%, \mathrm{I}^{2}=87.5 \%$ ) (Figure 6 ). In both age groups, more children were taken for formal care $\left(41.2 \%\right.$ of neonates, $95 \% \mathrm{CI}=29.3 \%-53.5 \%, \mathrm{I}^{2}=97.2 \%$ and $73.1 \%$ of infants and young children, $\left.95 \% \mathrm{CI}=66.5 \%-79.2 \% \mathrm{I}^{2}=96.5 \%\right)$ than informal care ( $12.7 \%$ of neonates, $95 \% \mathrm{CI}=6.5 \%-20.3 \%$, $\mathrm{I}^{2}=94.7 \%$, and $23.5 \%$ of infants and young children, $\left.95 \% \mathrm{CI}=14.2 \%-34.3 \%, \mathrm{I}^{2}=98.6 \%\right)$. A small minority of children died before setting out or arriving at a care facility $(5.8 \%$ of neonates, $95 \% \mathrm{CI}=3.5 \%$ $8.6 \%, \mathrm{I}^{2}=66.4 \%$ and $10.4 \%$ of infants and young children, $95 \% \mathrm{CI}=6.1 \%-15.7 \%, \mathrm{I}^{2}=94.3 \%$ ).

\section{At care facilities}

A minority of neonates in their final illnesses were alive when they arrived at a care facility $(36.5 \% 95 \%$ $\mathrm{CI}=25.2 \%-48.5 \%, \mathrm{I}^{2}=93.8 \%$ ) whereas the majority of infants and young children made it to a formal health care facility alive $\left(58.7 \%, 48.0 \%-68.9 \%, \mathrm{I}^{2}=97.5 \%\right)$. However, in both age groups, this represented a large majority of those who sought formal care ( $85.8 \%$ of neonates, $95 \% \mathrm{CI}=76.5 \%-93.1 \%, \mathrm{I}^{2}=84.0 \%$ and $88.4 \%$ of infants and young children, $\left.95 \% \mathrm{CI}=79.4-95.3, \mathrm{I}^{2}=97.0 \%\right)$. Also, in both age groups most of those children who arrived alive left the care facility alive ( $62.9 \%$ of neonates, $95 \% \mathrm{CI}=40.9 \%-82.4 \%$, $\mathrm{I}^{2}=94.6 \%$ and $69.6 \%$ of infants and young children, $95 \% \mathrm{CI}=59.6-78.7, \mathrm{I}^{2}=95.5 \%$, Figure 7$)$, though only a minority of those discharged were referred for further care $(30.7 \%$ of neonates, $95 \% \mathrm{CI}=7.1 \%$ $61.3 \%, \mathrm{I}^{2}=94.7 \%$ and $34.9 \%$ of infants and young children, $\left.95 \% \mathrm{CI}=15.1-57.9, \mathrm{I}^{2}=98.7 \%\right)$ ). Most carers offered referral for their baby accepted it $\left(65.9 \%, 95 \% \mathrm{CI}=49.3 \%-81.0 \%, \mathrm{I}^{2}=50.3 \%\right)$. The same was true for caregivers of infants and young children $\left(69.3 \%, 95 \% \mathrm{CI}=57.7-79.9, \mathrm{I}^{2}=85.6 \%\right)$.

\section{Exploration of heterogeneity}

Heterogeneity was high even within subgroups. This is common in meta-analyses of proportions. Meta-regression results are presented in Table 3. Heterogeneity in place of death was partly explained by 


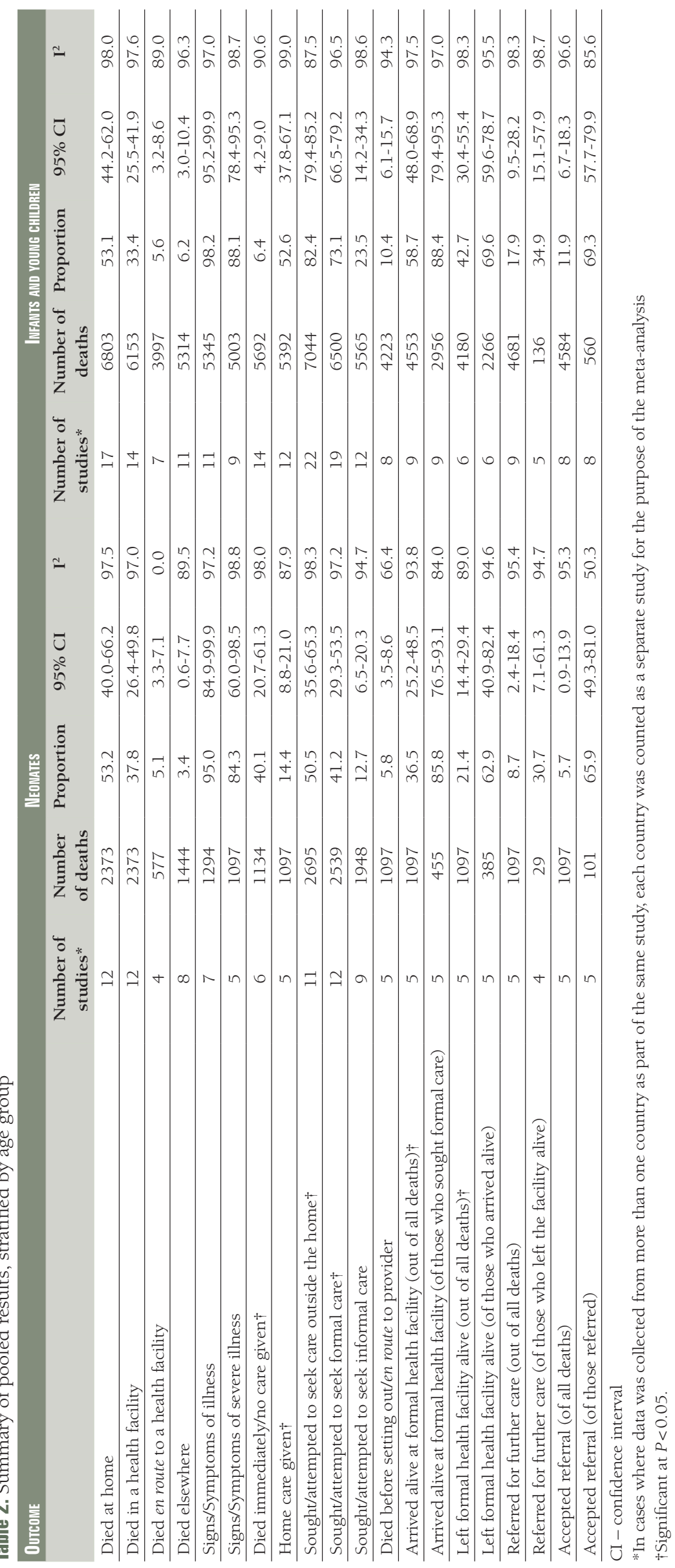

user-fee policy (adjusted co-efficient for death at home $0.3895 \% \mathrm{CI}=0.06-0.70$, $P=0.020, R^{2}=11.00 \%$ ), whereas variance in care-seeking patterns was partly accounted for by age (adjusted co-efficient for whether care was sought outside the home $0.49,95 \% \mathrm{CI}=0.21-0.77, P=0.001$ ) (see Table 3 for each stage of the care pathway). Neither national income status nor user-fee policy was consistently associated with differences in care-seeking patterns (Tables S2 and S3 in Online Supplementary Document).

\section{DISCUSSION}

\section{Summary of results}

This review and meta-analysis demonstrated that approximately half of deaths of neonates, infants and young children occur at home in those countries for which place of death data are available across sub-Saharan Africa. In both age groups, signs and symptoms of illness were reported in the large majority of children (over 95\%). However, whereas care-seeking for dying neonates is poor, many older children die at home despite their caregivers engaging formal care services before they die.

Forty percent of neonates received no care of any sort during their final illness. Only half of caregivers attempted to seek care outside the home, and fewer still sought formal health care. Only a third of all neonates arrived at formal health care facilities alive, though most studies which reported on this stage of the care pathway excluded neonates who were born and died in a health care facility without being discharged. It is probable that this would be much higher proportion if one were to include those who were alive in utero when the mother presented for delivery at the health facility. Health facilities discharged almost two thirds of the ill neonates, with less than a third of those who were discharged referred on for further care. These findings suggest that modifiable factors contributing to neonatal deaths include a failure of caregivers to recognise early signs of illness, or to appreciate the severity of neonatal illness (even if they report signs and symptoms of disease), which contribute to delays in seeking health care. Barriers to care-seeking resulting in even minor delays can be fatal as neonatal illness tends 


\section{Sought/attempted to seek care}

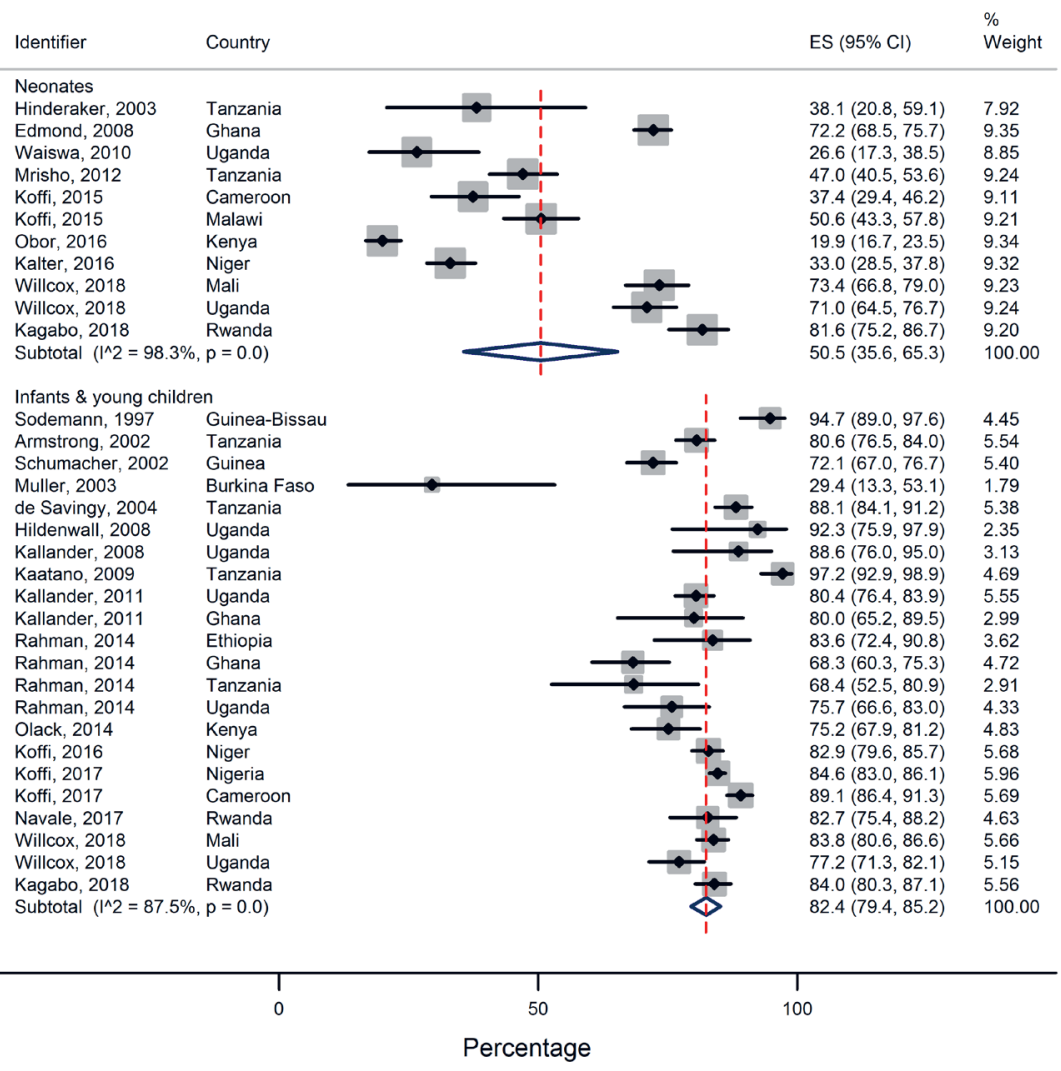

Figure 6. Proportion of caregivers who sought or attempted to seek care outside the home for their child during the final illness, by age group.

\section{Proportion who left health facility alive (of those who arrived alive)}

\begin{tabular}{ll} 
Identifier & Country \\
\hline Neonates & \\
Koffi, 2015 & Cameroon \\
Koffi, 2015 & Malawi \\
Kalter, 2016 & Niger \\
Willcox, 2018 & Mali \\
Willcox, 2018 & Uganda \\
Subtotal $(\mid \wedge 2=94.6 \%, p=0.0)$
\end{tabular}

Infants \& young children

$\begin{array}{ll}\text { Sodemann, 1997 } & \text { Guinea-Bissau } \\ \text { Koffi, 2016 } & \text { Niger } \\ \text { Koffi, 2017 } & \text { Nigeria } \\ \text { Koffi, 2017 } & \text { Cameroon } \\ \text { Willcox, 2018 } & \text { Mali } \\ \text { Willoox, 2018 } & \text { Uganda }\end{array}$

Subtotal $(1 \wedge 2=95.5 \%, p=0.0)$
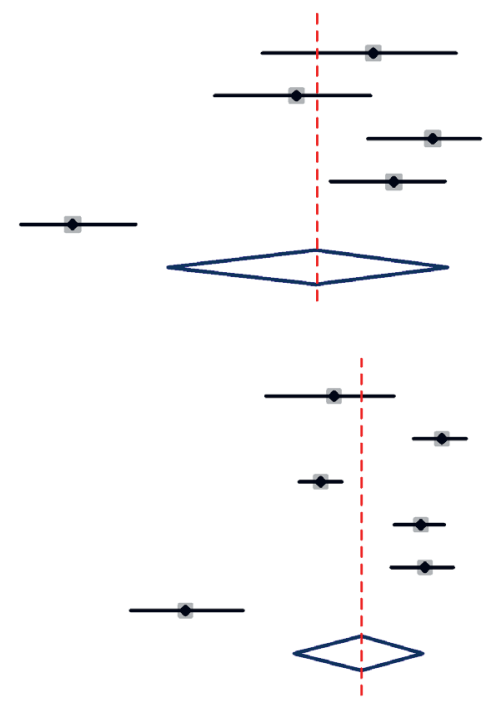

ES $(95 \% \mathrm{Cl})$

Weight

$\begin{array}{ll}71.4(54.9,83.7) & 18.98 \\ 60.0(47.9,71.0) & 19.96 \\ 80.2(70.6,87.3) & 20.27 \\ 74.5(65.0,82.1) & 20.38 \\ 26.7(19.1,36.1) & 20.41 \\ 62.9(40.9,82.4) & 100.00\end{array}$

$\begin{array}{ll}65.6(55.5,74.5) & 15.25 \\ 81.6(77.4,85.2) & 17.11 \\ 63.6(60.4,66.7) & 17.53 \\ 78.5(74.5,81.9) & 17.25 \\ 79.1(74.1,83.3) & 16.93 \\ 43.5(35.3,52.1) & 15.92 \\ 69.6(59.6,78.7) & 100.00\end{array}$

\begin{tabular}{ccc|c}
\hline & 1 & 1 & 100 \\
0 & 50 & Percentage &
\end{tabular}

Figure 7. Proportion of children who left the first health facility alive, by age group. 


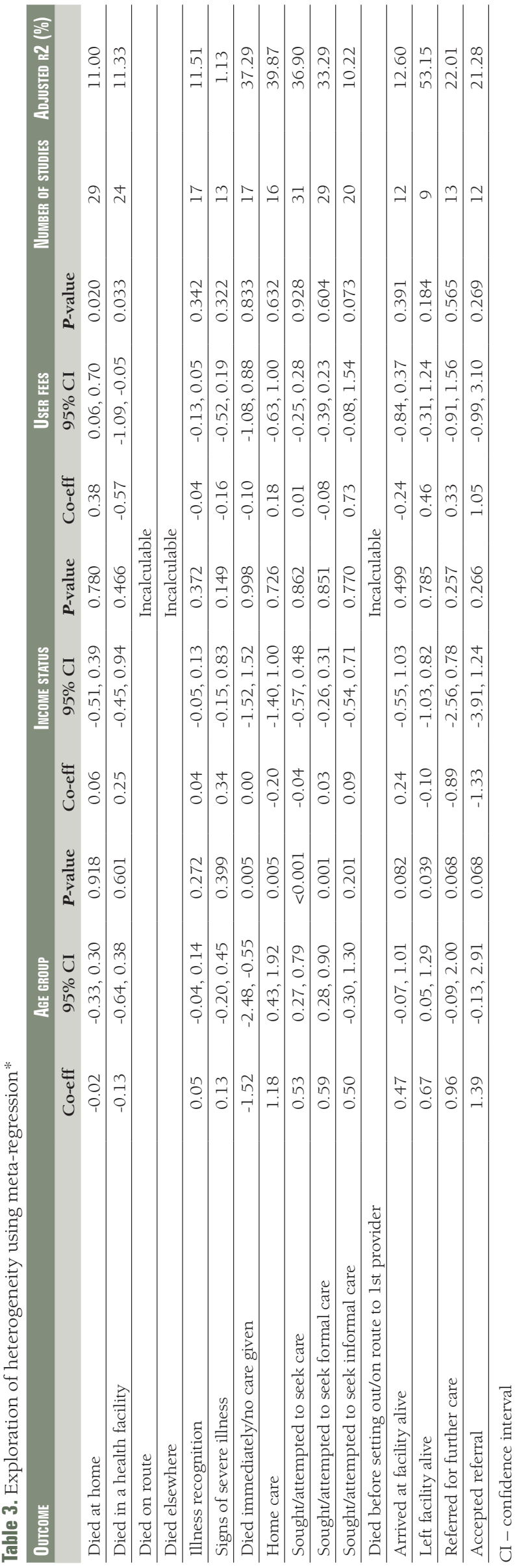

to progress rapidly which reduces the likelihood of reaching a facility alive compared to older children. However, high rates of discharge and low referral rates might suggest that when caregivers sought and received care it was inadequate.

In contrast, only a small minority of children older than one month died without receiving care of any sort. Some caregivers sought informal care, but almost three quarters of the children were taken to a formal health care provider and a majority arrived at that provider alive. Healthcare facilities discharged over two thirds of these children, and of those only a third were referred for further care. This would suggest that for older children, modifiable factors might be more concentrated at the health facility level.

Statistical heterogeneity was high, even across sub-groups. This is common in studies that pool proportions and continuous measures. Proportions are less stable between settings than ratio effect measures. Thresholds of $\mathrm{I}^{2}$ used for pooling trials are not appropriate for meta-analysis of continuous variables [48]. Furthermore, three factors may have contributed to the statistical heterogeneity across sub-groups: first, heterogeneity at certain stages of the care pathway may have arisen due to narrow confidence intervals for individual studies [48] eg, illness recognition by caregivers of infants and young children was high despite the total range of findings across all studies for post-neonatal deaths being 79.3\%$100 \%$. Similarly, the range reported for neonates being given home care was $5.1 \%-27.8 \%$. The differences in these proportions are clinically small and would not change the practical interpretation of the results. Second, outlier studies contributed to heterogeneity at some stages of the care pathway; eg, for the proportion of infants and young children who died immediately or did not receive any care, the full range across 13 studies was $0.9 \%-19.9 \%$, but there was one "outlier" study from Burkina Faso with a 95\% confidence interval of $31.0 \%$ and $73.8 \%$ (Figure 5). Similarly, regarding the proportion of infants and young children whose parents sought/ attempted to seek care, most studies ranged from 52.5\%98.9\%, however the same study from Burkina Faso reported much lower rates of attempted care-seeking in the same age group ( $95 \% \mathrm{CI}=13.3 \%-53.1 \%$ ). This was the smallest of all the studies we included (investigating only 17 deaths) and was also one of the earliest (conducted in 1999) in a very remote part of Burkina Faso, which probably explains the low levels of care-seeking and the very wide confidence interval. Third, while we tried to account for certain "macro" differences, such as national income and user-fee policy, these were nonetheless crude markers of known social determinants of health. We were unable to adjust for rural or urban setting as there was limited data from urban settings to use as a comparator (only 2 studies), and data on other known predictors of care-seeking behaviour - such as distance to clinics and levels of education - was simply unavailable consistently across the included studies. The question of context might explain the seemingly bimodal pattern of home deaths in settings with user-fees (Appendix S4 in in Online Supplementary Document): almost all deaths in the studies from Ethiopia [37], Kenya [18] and Guinea [20] appeared to happen at home. In 
Ethiopia, the authors suggested that the high proportions of home deaths might reflect high levels of unattended home births in this community, and limited access to health facilities due to terrain and location of villages far from main roads [37]. In Kenya, home deaths occurred despite a majority having sought care outside the home. Important contextual factors here were low follow-up and referral rates from formal health providers, underuse of community health workers and a preference for traditional healers [18]. In Guinea, home deaths were attributed to a combination of a lack of trained traditional birth attendants for home births, poor recognition of danger signs and poor care-seeking outside the home [20]. Both the studies in Kenya and Guinea were conducted in the late 1990s in rural areas, prior to the expansion of primary care initiatives such as the Integrated Management of Childhood Illness (IMCI); it is possible that care-seeking behaviour and place of death has changed in more recent years.

\section{Comparison with previous studies}

Our findings are consistent with previous studies that highlighted failures to recognise signs of illness, particularly in neonates [49-51]. As our study included only children who died, care-seeking would have been appropriate for most if not all of them. Failure to provide or seek care for a child despite the presence of symptoms and signs of illness has been linked to low health literacy in the communities where these studies were conducted [35]. As noted by Koffi, Maina, Yaroh et al (2016), a lack of care-seeking could suggest that caregivers do not appreciate the significance of clinical features as markers of severe illness requiring urgent medical care [52]. Different conceptions of the aetiology of disease, and cultural beliefs regarding appropriate treatment providers also contribute to delays in care-seeking $[43,53,54]$. Low levels of maternal education may contribute to the overall mortality risk of children, and also to the specific care-seeking patterns demonstrated $[4,45,52]$.

We also found relatively high rates of care-seeking during a child's final illness - particularly for infants and young children. Multiple studies have commented on similar findings, emphasising that attention needs to be directed to modifiable factors at the health care facility level $[5,17,23]$. The low referral rates we found across both age groups have also been noted before, though without adequate explanation $[4,52]$. Some studies have suggested that barriers to referral include lack of transport, cost and distance to the referral facility [52], however our findings suggest these may not be insurmountable obstacles for caregivers as demonstrated by the high rates of referral acceptance when referral is made. Our findings are consistent with other studies which have suggested that staff who are the first point of contact, including community health workers and primary health care facility staff, might benefit from further training on the recognition of danger signs, and on familiarisation with indications for referral and the establishment of clear referral guidelines and pathways $[4,18]$.

Because we have brought together all the available evidence, we were able to analyse factors across settings. No differences were noted in place of death or care-seeking behaviour between countries of different income status. User-fees were associated with a higher proportion of home deaths (69\% in settings with user-fees as opposed to $44 \%$ in settings without user-fees), however this association is difficult to interpret given the bimodal distribution pattern for home deaths in countries with user-fees (as shown in Appendix S4 in Online Supplementary Document). Furthermore, no statistically significant differences were seen across the care pathway based on user-fees, suggesting that despite charges caregivers sought care - although there was a trend towards higher rates of seeking formal care in settings without user-fees (65\%, compared to $53 \%$ in countries with user-fees), and higher rates of informal care in settings with user-fees (25\%) compared to those without user-fees (11\%). Many studies highlight cost as a barrier to care-seeking [35,52]. It is possible that user-fees also affect the decision to accept hospital admission, or caregivers' abilities to follow home recommendations including the purchase of medications - neither of which we captured in this review, but which would warrant further investigation to understand how different health system financing models affect specific care-seeking decisions in childhood illness.

\section{Strengths and limitations}

This study had three important strengths and corresponding limitations. First, we sought to pool studies from different settings in sub-Saharan Africa. This has contributed to the findings of high heterogeneity. Whilst this means it is unlikely that there would be a single numerical answer for every setting, it also allows us to draw conclusions with a broad evidence base and to compare the settings to attempt to understand reasons for the differences.

Second, we included only children who had died. This meant that there was no comparison made to children who survived, and so we cannot determine whether there are differences at specific stages of 
the pathway that might increase mortality risk. The strength of including only children who died is that it allows us to say that the included children should have had medical care sought and provided. It is likely that the children were seriously unwell so this should have been recognised, though it is possible that a small minority of children died from sudden infant death syndrome and so would have appeared well prior to death.

Finally, by pooling evidence across multiple study designs we were able to present data across each of the stages of the care pathways as defined by the Pathways to Survival framework. However, we were unable to disaggregate the databased on place of death, and so drawing direct conclusions about why high proportions of children die at home across sub-Saharan Africa remains difficult. In some studies, we were also unable to identify whether they included or excluded neonates who had arrived alive at a health facility in utero, and were delivered, but died prior to discharge.

\section{Implications and recommendations for policy}

We found evidence consistent with neonates dying quickly or without recognition of their illness. The implication of these patterns is that health care systems should target all neonates for surveillance, irrespective of the concerns of parents. A system that provides monitoring of health for neonates could be a post-natal clinic or visitor scheme, or might be a target for technological solutions [55]. Health education interventions to improve caregiver recognitions of "danger signs" would also be of value. Unfortunately, it is possible that many of those children who reached formal care did not get adequate quality care, and many were discharged without referral. However, the Pathways to Survival framework is limited in its ability to assess care quality and the appropriateness of referral. Other sources of information including facility-based audits and confidential enquiries into child deaths are better placed to assess care quality and suggest strategies to improve care at the health facility level. High quality formal care might also improve the proportion of caregivers who seek care.

The majority of caregivers of older children sought and arrived at formal care, though informal and home care was inappropriately high as well. This is consistent with caregivers recognizing severe illness. We found a widespread pattern of discharging most of the children without referral, all of whom had an illness that ultimately killed them. This may be a function of poor quality care, which should serve as the focus for future interventions to address preventable mortality in infants and young children [56]. However, further work would also be required to fully understand whether the discharge of ill children is at the caregiver's request which might reflect differences in traditional beliefs around preferred place of death or practical considerations such as the relative costs of transporting a terminally ill but alive child (which can be a normal taxi fare) compared to the much higher costs of transporting a dead body [57]. Caregivers may also want to avoid death occurring in a health facility in cases where the cause of death entered on the death certificate would cause stigma for the family, as has been noted in HIV/AIDS-related deaths $[58,59]$.

While we found some evidence that user-fees may be associated with higher proportions of home deaths, the mechanism is unclear, and this effect appears to vary across settings. Other research has shown an increase in treatment-seeking for childhood illness from formal health care providers when user-fees are removed [60-62]. Further research is required to better understand the impact of user-fees in different contexts on care-seeking, referral and admissions, and subsequent place of death before policy recommendations can be made.

\section{Implications for clinical practice}

Clinicians working in low-and-middle income settings across sub-Saharan Africa should be aware that a large proportion of the children who die are seen by clinical staff and sent home. They should therefore consider clear safety-netting advice for caregivers, with instructions for what should prompt re-presentation.

\section{Implications for research}

Researchers conducting population-based research should consider reporting deaths according to the Pathways to Survival framework, and so should ensure that the data collection tools used to investigate deaths include the necessary information to report on each stage of the pathway. It is also important to standardise definitions for each stage of the care pathway and the questions used to calculate the relevant numerator and denominator. For example, illness recognition may refer to the presence or reporting of 
symptoms in response to a verbal-autopsy questionnaire or it may require that caregivers indicate that such symptoms were indicative of illness requiring medical attention. Similarly, when asking whether care was sought outside the home, it is necessary to clarify whether this includes caregivers who intended to seek care but were delayed or unable to reach a provider. With regards to neonatal deaths, reporting should be standardised to either include or exclude neonates who were born and died in a health facility without being discharged. The definitions used in this study (available as Appendix S5 in Online Supplementary Document) might serve as a starting point for those undertaking new research.

Finally, studies should be designed to capture representative samples and take action if there are reasons to suspect this has not been done. Our modified Axis tool could be used for assessment of study design for the design, reporting and assessment of future studies of under- 5 deaths. Further studies of under-5 deaths should be carried out in under-represented areas of sub-Saharan Africa (Figure 2) and should include data on quality of care in addition to care-seeking behaviour.

\section{CONCLUSIONS}

This study is the first to present a common picture for care-seeking behaviour in fatal childhood illness across sub-Saharan Africa, across each of the stages of the Pathways to Survival framework. Despite high heterogeneity, findings nevertheless suggest that there are differences in care-seeking behaviour between neonatal deaths and deaths of infants and young children. Understanding such care-seeking patterns is important in highlighting targets for interventions to reduce under-5 mortality across the region, including the need to improve recognition of danger signs in neonates, increasing the quality of care for both neonates and children 1-59 months and ensuring safety-netting, appropriate referral and improved post-discharge counselling and follow-up by health care providers.

\footnotetext{
Acknowledgements: We would like to thank Nia Roberts for her input on refining the literature search strategy, Constantinos Koshiaris who advised on appropriate meta-analysis methods and Beth Stuart who reviewed the results and relevant discussion of the heterogeneity of the data. We would like to acknowledge the researchers and study teams who conducted the original research on which articles included in this review are based.

Funding: JL is an NIHR In-Practice fellow. JP is funded by the Rhodes Scholarship. The salary of MLW was funded by the National Institute of Health Research (NIHR), under grant CL-2016-26-005.

Authorship contribution: JP and AH conceived of the study. JP, JL and MW drafted the review protocol with inputs from AH. JP and MW developed the literature search strategy. JP and JL screened all titles, abstracts and full texts and completed data extraction. JP conducted data synthesis and meta-analysis, and drafted the manuscript. JL, MW and AH reviewed the manuscript and gave final approval for publication.

Competing interests: The authors completed the Unified Competing Interest form at www.icmje.org/coi_disclosure.pdf (available upon request from the corresponding author), and declare no conflicts of interest.

Additional material

Online Supplementary Document
}

1 United Nations Inter-agency Group for Child Mortality Estimation. (UN, IGME). 'Levels \& Trends in Child Mortality: Report 2018, Estimates developed by the United Nations Inter-agency Group for Child Mortality Estimation. 2018. Available: https://data.unicef.org/wp-content/uploads/2018/10/Child-Mortality-Report-2018.pdf. Accessed: 19 March 2019.

2 UNICEF. The State of the World's Children 2017: Children in a Digital World. 2017. Available: https://www.unicef.org/ publications/files/SOWC_2017_ENG_WEB.pdf. Accessed: 25 June 2019.

3 Sustainable Development Goals. 17 goals to transform our world. 2015. Available: http://www.un.org/sustainabledevelopment/health/. Accessed 5 January 2016.

4 Koffi AK, Kalter HD, Loveth EN, Quinley J, Monehin J, Black RE. Beyond causes of death: The social determinants of mortality among children aged 1-59 months in Nigeria from 2009 to 2013. PLoS One. 2017;12:e0177025. Medline:28562610 doi:10.1371/journal.pone.0177025

5 Källander K, Kadobera D, Williams TN, Nielsen RT, Yevoo L, Mutebi A, et al. Social autopsy: INDEPTH Network experiences of utility, process, practices, and challenges in investigating causes and contributors to mortality. Popul Health Metr. 2011;9:44. Medline:21819604 doi:10.1186/1478-7954-9-44

6 Koffi AK, Maina A, Yaroh AG, Habi O, Bensaid K, Kalter HD. Social determinants of child mortality in Niger: Results from the 2012 National Verbal and Social Autopsy Study. J Glob Health. 2016;6:010603. Medline:26955473 doi:10.7189/ jogh.06.010603 
7 Moyer CA, Johnson C, Kaselitz E, Aborigo R. Using social autopsy to understand maternal, newborn, and child mortality in low-resource settings: a systematic review of the literature. Glob Health Action. 2017;10:1413917. Medline:29261449 doi:10.1080/16549716.2017.1413917

8 Thaddeus S, Maine D, Babille M, Koffi AK, Black RE, Thaddeus S, et al. Too far to walk: Maternal mortality in context. Soc Sci Med. 1994;38:1091-110. Medline:8042057 doi:10.1016/0277-9536(94)90226-7

9 Waiswa P, Kalter HD, Jakob R, Black RE. Increased use of social autopsy is needed to improve maternal, neonatal and child health programmes in low-income countries. Bull World Health Organ. 2012;90:403-403A. Medline:22690025 doi:10.2471/BLT.12.105718

10 Waldman R, Campbell CC, Steketee RW. Overcoming Remaining Barriers: The Pathway to Survival. Arlington; 1996. Available: https://pdf.usaid.gov/pdf_docs/PNABZ644.pdf. Accessed: 19 March 2019.

11 The World Bank. World Bank Country and Lending Groups. Available: https://datahelpdesk.worldbank.org/knowledgebase/articles/906519. Accessed: 20 June 2019.

12 Downes MJ, Brennan ML, Williams HC, Dean RS. Development of a critical appraisal tool to assess the quality of cross-sectional studies (AXIS). BMJ Open. 2016;6:e011458. Medline:27932337 doi:10.1136/bmjopen-2016-011458

13 Nyaga VN, Arbyn M, Aerts M. Metaprop: a Stata command to perform meta-analysis of binomial data. Arch Public Health. 2014;72:39. Medline:25810908 doi:10.1186/2049-3258-72-39

14 Joseph Newton EH, Nicholas Cox EJ, Beck N, Bellocco R, Buis ML, Colin Cameron A, et al. Meta-regression in Stata. Stata J. 2008;8:493-519. doi:10.1177/1536867X0800800403

15 Moher D, Liberati A, Tetzlaff J, Altman DG, Group TP. Preferred Reporting Items for Systematic Reviews and Meta-Analyses: The PRISMA Statement. PLoS Med. 2009;6:e1000097. Medline:19621072 doi:10.1371/journal.pmed.1000097

16 Snow RW, Schellenberg JR, Forster D, Mung'ala VO, Marsh K. Factors influencing admission to hospital during terminal childhood illnesses in Kenya. Int J Epidemiol. 1994;23:1013-9. Medline:7860152 doi:10.1093/ije/23.5.1013

17 Sodemann M, Jakobsen MS, Molbak K, Alvarenga ICJ, Aaby P. High mortality despite good care-seeking behaviour: A community study of childhood deaths in Guinea-Bissau. Bull World Health Organ. 1997;75:205-12. Medline:9277007

18 Garg R, Omwomo W, Witte JM, Lee LA, Deming MS, et al. Care seeking during fatal childhood illnesses: Siaya District, Kenya, 1998. Am J Public Health. 2001;91:1611-3. Medline:11574320 doi:10.2105/AJPH.91.10.1611

19 Armstrong Schellenberg JRM, Nathan R, Abdulla S, Mukasa O, Marchant TJ, Tanner M, et al. Risk factors for child mortality in rural Tanzania. Trop Med Int Health. 2002;7:506-11. Medline:12031072 doi:10.1046/j.1365-3156.2002.00888.x

20 Schumacher R, Swedberg E, Diallo M, Keita D, Kalter H., Pasha O. Mortality study in Guinea: investigating the causes of death in children under 5. 2002.

21 Hinderaker SG, Olsen BE, Bergsjo PB, Gasheka P, Lie RT, Havnen J, et al. Avoidable stillbirths and neonatal deaths in rural Tanzania. BJOG. 2003;110:616-23. Medline:12798482 doi:10.1046/j.1471-0528.2003.02153.x

22 Müller O, Traore C, Becher H, Kouyate B. Malaria morbidity, treatment-seeking behaviour, and mortality in a cohort of young children in rural Burkina Faso. Trop Med Int Health. 2003;8:290-6. Medline:12667146 doi:10.1046/j.13653156.2003.01030.x

23 de Savigny D, Mayombana C, Mwageni E, Masanja H, Minhaj A, Mkilindi Y, et al. Care-seeking patterns for fatal malaria in Tanzania. Malar J. 2004;3:27. Medline:15282029 doi:10.1186/1475-2875-3-27

24 Beiersmann C, Sanou A, Wladarsch E, De Allegri M, Kouyate B, Muller O. Malaria in rural Burkina Faso: local illness concepts, patterns of traditional treatment and influence on health-seeking behaviour. Malar J. 2007;6:106. Medline:17686147 doi:10.1186/1475-2875-6-106

25 Kamugisha ML, Gesase S, Mlwilo TD, Mmbando BP, Segeja MD, Minja DT, et al. Malaria specific mortality in lowlands and highlands of Muheza district, north-eastern Tanzania. Tanzan Health Res Bull. 2007;9:32-7. Medline:17547098 doi:10.4314/thrb.v9il.14289

26 Edmond KM, Quigley MA, Zandoh C, Danso S, Hurt C, Agyei SO, et al. Aetiology of stillbirths and neonatal deaths in rural Ghana: Implications for health programming in developing countries. Paediatr Perinat Epidemiol. 2008;22:430-7. Medline:18782251 doi:10.1111/j.1365-3016.2008.00961.x

27 Hildenwall H, Tomson G, Kaija J, Pariyo G, Peterson S. I never had the money for blood testing - Caretakers' experiences of care-seeking for fatal childhood fevers in rural Uganda - a mixed methods study. BMC Int Health Hum Rights. 2008;8:12. Medline:19055738 doi:10.1186/1472-698X-8-12

28 Källander K, Hildenwall H, Waiswa P, Galiwango E, Peterson S, Pariyo G. Delayed care seeking for fatal pneumonia in children aged under five years in Uganda: a case-series study. Bull World Health Organ. 2008;86:332-8. Medline:18545734 doi:10.2471/BLT.07.049353

29 Kaatano GM, Mashauri FM, Kinung'hi SM, Mwanga JR, Malima RC, Kishamawe C, et al. Patterns of malaria related mortality based on verbal autopsy in Muleba District, north-western Tanzania. Tanzan J Health Res. 2009;11:210-8. Medline:20734701

30 Waiswa P, Kallander K, Peterson S, Tomson G, Pariyo GW, et al. Using the three delays model to understand why newborn babies die in eastern Uganda. Trop Med Int Health. 2010;15:964-72. Medline:20636527 doi:10.1111/j.13653156.2010.02557.x

31 Manortey S, Carey A, Ansong D, Harvey R, Good B, Boaheng J, et al. Verbal autopsy: An analysis of the common causes of childhood death in the Barekese sub-district of Ghana. J Public Health Afr. 2011;2:e18. Medline:28299059 doi:10.4081/ jphia.2011.e18

32 Mrisho M, Schellenberg D, Manzi F, Tanner M, Mshinda H, Shirima K, et al. Neonatal deaths in rural southern Tanzania: care-seeking and causes of death. ISRN Pediatr. 2012;2012:953401. Medline:22518328 doi:10.5402/2012/953401 
33 Olack B, Feikin DR, Cosmas LO, Odero KO, Okoth GO, Montgomery JM, et al. Mortality trends observed in population-based surveillance of an urban slum settlement, Kibera, Kenya, 2007-2010. PLoS One. 2014;9:e85913. Medline:24489678 doi:10.1371/journal.pone.0085913

34 Rahman AE, Moinuddin M, Molla M, Worku A, Hurt L, Kirkwood B, et al. Childhood diarrhoeal deaths in seven low- and middle-income countries. Bull World Health Organ. 2014;92:664-71. Medline:25378757 doi:10.2471/BLT.13.134809

35 Koffi AK, Libite P-R, Moluh S, Wounang R, Kalter HD. Social autopsy study identifies determinants of neonatal mortality in Doume, Nguelemendouka and Abong-Mbang health districts, Eastern Region of Cameroon. J Glob Health. 2015;5:010413. Medline:26171142 doi:10.7189/jogh.05.010413

36 Koffi AK, Mleme T, Nsona H, Banda B, Amouzou A, Kalter HD, et al. Social autopsy of neonatal mortality suggests needed improvements in maternal and neonatal interventions in Balaka and Salima districts of Malawi. J Glob Health. 2015;5:010416. Medline:27698997

37 Assefa N, Lakew Y, Belay B, Kedir H, Zelalem D, Baraki N, et al. Neonatal mortality and causes of death in Kersa Health and Demographic Surveillance System (Kersa HDSS), Ethiopia, 2008-2013. Matern Health Neonatol Perinatol. 2016;2:7. Medline:27437118 doi:10.1186/s40748-016-0035-8

38 D’Ambruoso L, Kahn K, Wagner RG, Twine R, Spies B, van der Merwe M, et al. Moving from medical to health systems classifications of deaths: extending verbal autopsy to collect information on the circumstances of mortality. Glob Health Res Policy. 2016;1:2. Medline:29202052 doi:10.1186/s41256-016-0002-y

39 Kalter HD, Yaroh AG, Maina A, Koffi AK, Bensaïd K, Amouzou A, et al. Verbal/social autopsy study helps explain the lack of decrease in neonatal mortality in Niger, 2007-2010. J Glob Health. 2016;6:010604. Medline:26955474 doi:10.7189/ jogh.06.010604

40 Obor D, Otieno PJR, Verani J, Odhiambo F, Laserson K. Using the kemri-cdc health and demographic surveillance system to demonstrate the changing neonatal mortality rate between 2003 and 2012 in rural western Kenya. Am J Trop Med Hyg. 2016;95(5 Supplement 1):263.

41 Rosario EVN, Costa D, Timoteo L, Rodrigues AA, Varanda J, Nery SV, et al. Main causes of death in Dande, Angola: results from Verbal Autopsies of deaths occurring during 2009-2012. BMC Public Health. 2016;16:719. Medline:27491865 doi:10.1186/s12889-016-3365-6

42 Bogale TN, Worku AG, Bikis GA, Kebede ZT. Why gone too soon? Examining social determinants of neonatal deaths in northwest Ethiopia using the three delay model approach. BMC Pediatr. 2017;17:216. Medline:29282018 doi:10.1186/ s12887-017-0967-9

43 Koffi AK, Wounang RS, Nguefack F, Moluh S, Libite P-R, Kalter HD. Sociodemographic, behavioral, and environmental factors of child mortality in Eastern Region of Cameroon: results from a social autopsy study. J Glob Health. 2017;7:010601. Medline:28400957 doi:10.7189/jogh.07.010601

44 Navale S, Habumugisha L, Amoroso C, Sayinzoga F, Gupta N, Hirschhorn LR. Exploring Drivers of infant deaths in rural Rwanda through verbal social autopsy. Ann Glob Health. 2017;83:756-66. Medline:29248092 doi:10.1016/j. aogh.2017.10.029

45 Kagabo DM, Kirk CM, Bakundukize B, Hedt-Gauthier BL, Gupta N, Hirschhorn LR, et al. Care-seeking patterns among families that experienced under-five child mortality in rural Rwanda. PLoS One. 2018;13:e0190739. Medline:29320556 doi:10.1371/journal.pone.0190739

46 Willcox ML, Kumbakumba E, Diallo D, Mubangizi V, Kirabira P, Nakaggwa F, et al. Circumstances of child deaths in Mali and Uganda: a community-based confidential enquiry. Lancet Glob Health. 2018;6:e691-702. Medline:29773123 doi:10.1016/S2214-109X(18)30215-8

47 Okonofua F, Lambo E, Okeibunor J, Agholor K. Advocacy for free maternal and child health care in Nigeria-Results and outcomes. Health Policy. 2011;99:131-8. Medline:20727612 doi:10.1016/j.healthpol.2010.07.013

48 Alba AC, Alexander PE, Chang J, MacIsaac J, DeFry S, Guyatt GH. High statistical heterogeneity is more frequent in meta-analysis of continuous than binary outcomes. J Clin Epidemiol. 2016;70:129-35. Medline:26386323 doi:10.1016/j. jclinepi.2015.09.005

49 Geldsetzer P, Williams TC, Kirolos A, Mitchell S, Ratcliffe LA, Kohli-Lynch MK, et al. The Recognition of and care seeking behaviour for childhood illness in developing countries: A systematic review. Semple MG, editor. PLoS One. 2014;9:e93427.

50 Kibaru EG, Otara AM. Knowledge of neonatal danger signs among mothers attending well baby clinic in Nakuru Central District, Kenya: cross sectional descriptive study. BMC Res Notes. 2016;9:481. Medline:27782863 doi:10.1186/ s13104-016-2272-3

51 Sandberg J, Odberg Pettersson K, Asp G, Kabakyenga J, Agardh A. Inadequate knowledge of neonatal danger signs among recently delivered women in southwestern rural Uganda: a community survey. PLoS One. 2014;9:e97253. Medline:24824364 doi:10.1371/journal.pone.0097253

52 Koffi AK, Maina A, Yaroh AG, Habi O, Bensaïd K, Kalter HD. Social determinants of child mortality in Niger: Results from the 2012 National Verbal and Social Autopsy Study. J Glob Health. 2016;6:010603. Medline:26955473 doi:10.7189/ jogh.06.010603

53 Hill Z, Kendall C, Arthur P, Kirkwood B, Adjei E. Recognizing childhood illnesses and their traditional explanations: Exploring options for care-seeking interventions in the context of the IMCI=strategy in rural Ghana. Trop Med Int Health. 2003;8:668-76. Medline:12828551 doi:10.1046/j.1365-3156.2003.01058.x

54 Muela SH, Ribera JM, Tanner M. Fake malaria and hidden parasites—the ambiguity of malaria. Anthropol Med. 1998;5:4361. Medline:26868738 doi:10.1080/13648470.1998.9964548 
55 Kirkwood BR, Manu A, ten Asbroek AH, Soremekun S, Weobong B, Gyan T, et al. Effect of the Newhints home-visits intervention on neonatal mortality rate and care practices in Ghana: a cluster randomised controlled trial. Lancet. 2013;381:2184-92. Medline:23578528 doi:10.1016/S0140-6736(13)60095-1

56 Wiens MO, Kumbakumba E, Larson CP, Moschovis PP, Barigye C, Kabakyenga J, et al. Scheduled follow-up referrals and simple prevention kits including counseling to improve post-discharge outcomes among children in Uganda: a proof-ofconcept study. Glob Health Sci Pract. 2016;4:422-34. Medline:27628107 doi:10.9745/GHSP-D-16-00069

57 Ware NC, Idoko J, Kaaya S, Biraro IA, Wyatt MA, Agbaji O, et al. Explaining adherence success in sub-Saharan Africa: an ethnographic study. PLoS Med. 2009;6:e11. Medline:19175285 doi:10.1371/journal.pmed.1000011

58 Dhai A, Dada M, Kirk G, McQuoid-Mason D. Confidentiality: a dying wish. S Afr Med J. 2001;91:123-7. Medline:11288389

59 Yudkin PL, Burger EH, Bradshaw D, Groenewald P, Ward AM, Volmink J. Deaths caused by HIV disease under-reported in South Africa. AIDS. 2009;23:1600-2. Medline:19521232 doi:10.1097/QAD.0b013e32832d4719

60 Druetz T, Fregonese F, Bado A, Millogo T, Kouanda S, Diabaté S, et al. Abolishing fees at health centers in the context of Community Case Management of malaria: What effects on treatment-seeking practices for febrile children in rural Burkina Faso? PLoS One. 2015;10:e0141306. Medline:26501561 doi:10.1371/journal.pone.0141306

61 Ansah EK, Narh-Bana S, Asiamah S, Dzordzordzi V, Biantey K, Dickson K, et al. Effect of removing direct payment for health care on utilisation and health outcomes in Ghanaian children: A randomised controlled trial. PLoS Med. 2009;6:e1000007. Medline:19127975 doi:10.1371/journal.pmed.1000007

62 Lagarde M, Palmer N. The impact of user fees on access to health services in low- and middle-income countries. Cochrane Database Syst Rev. 2011;4:CD009094. Medline:21491414 doi:10.1002/14651858.CD009094 